\title{
INFLUÊNCIA DO ESTRESSE HÍDRICO SOBRE O DESEMPENHO FISIOLÓGICO DE SEMENTES DE HÍBRIDOS SIMPLES DE MILHO-PIPOCA
}

\author{
Influence of water stress on the physiological performance of seeds \\ of simple hybrids of popcorn
}

\author{
Lia Mara Moterle', Carlos Alberto Scapim², Alessandro de Lucca e Braccini², \\ Marcos de Araújo Rodovalho ${ }^{1}$, Rafael Recanello Barreto ${ }^{3}$
}

\begin{abstract}
RESUMO
Objetivou-se, neste trabalho, avaliar o efeito do estresse hídrico induzido por polietileno glicol, na qualidade fisiológica das sementes de catorze híbridos simples de milho-pipoca. Para tanto, foi conduzido um experimento em que as sementes foram colocadas para germinar em substrato de papel-toalha, umedecido com soluções de polietileno glicol (PEG 6000), nos níveis de potencial osmótico de zero (controle) e -0,3 MPa. A qualidade fisiológica das sementes foi avaliada por meio do teste de germinação (primeira contagem e contagem final), do comprimento da raiz primária e da parte aérea das plântulas e da biomassa seca das plântulas. A diminuição do potencial hídrico do substrato é prejudicial à germinação das sementes e, principalmente, ao crescimento das plântulas de milho-pipoca. Os decréscimos nas variáveis analisadas dependeram dos híbridos avaliados. Os híbridos $\mathrm{G}$ e $\mathrm{K}$ foram os que se mostraram mais tolerantes ao estresse hídrico, enquanto que o híbrido $\mathrm{M}$ foi mais susceptível à seca. A tolerância ao estresse hídrico independe da qualidade inicial das sementes de milho-pipoca.
\end{abstract}

Termos para indexação: Zea mays, polietileno glicol, híbridos.

\begin{abstract}
The aim in this work was to evaluate the effect of the water stress induced by polyethylene glycol, in the physiological quality of seeds of fourteen hybrids of popcorn. For this, an experiment was carried out at laboratory in which the seeds were put to germinate in substratum of paper-towel, soaked with solutions of polyethylene glycol (PEG 6000) in the levels of osmotic potential of zero (control) and -0.3 MPa. The physiological quality of the seeds was evaluated through the germination test (first counting and final counting), length of the primary root and aerial part of the seedlings and dry biomass of seedlings. The decrease of the water potential of the substratum is harmful to the germination, mainly to the growth of seedlings of popcorn. The decreases in the analyzed variables depended on the appraised hybrid. The hybrids $\mathrm{G}$ and $\mathrm{K}$ were the ones that showed to be more tolerant to the water stress, while the one of the hybrid $\mathrm{M}$ was more susceptible to the drought. The tolerance to water stress does not depend on the initial quality of the popcorn seeds.
\end{abstract}

Index terms: Zea mays, polyethylene glycol, hybrids.

(Recebido em 23 de novembro de 2007 e aprovado em 31 de março de 2008)

\section{INTRODUÇÃO}

Existem diversos fatores que afetam o cultivo do milho-pipoca, entre eles a qualidade fisiológica das sementes utilizadas. A qualidade das sementes pode influenciar a uniformidade, a velocidade e a porcentagem de emergência em campo, além de apresentar reflexos sobre a produção final (DURÃES et al., 1993).

A germinação é uma das fases mais críticas do ciclo de vida das plantas. No processo de germinação das sementes, a absorção de água dá início a uma série de processos físicos, físiológicos e bioquímicos no interior da semente, os quais, na ausência de outro fator limitante, resultam na emergência da plântula (POPINIGIS, 1985).
Um dos principais problemas enfrentados na produção de milho-pipoca, assim como em outras culturas, refere-se a não obtenção de estande adequado. De acordo com Braccini et al. (1996), isso se deve a alguns fatores, tais como: o uso de sementes de baixa qualidade e condições adversas no início de estabelecimento da cultura.

Segundo Bansal et al. (1980), potenciais hídricos muito negativos, principalmente no início da embebição, promovem redução drástica na absorção de água pelas sementes, podendo inviabilizar a seqüência de eventos no processo germinativo. A baixa disponibilidade de água causa redução no crescimento, pela diminuição da expansão e do alongamento celular, devido ao decréscimo da turgescência (TAIZ \& ZEIGER, 2004).

${ }^{1}$ Engenheiros Agrônomos, Doutorandos - Departamento de Agronomia - Programa de Pós-Graduação em Agronomia/PGA - Universidade Estadual de Maringá/UEM - Avenida Colombo, Zona 7 - Cx. P. 5790-87020-900 - Maringá, PR - Imoterle@hotmail.com; marcos rodovalho@yahoo.com.br 2Engenheiros Agrônomos, Doutores, Professores Associado - Departamento de Agronomia - Programa de Pós-Graduação em Agronomia/PGA Universidade Estadual de Maringá/UEM - Avenida Colombo, Zona 7 - Cx. P. 5790 - 87020-900 - Maringá, PR - cascapim@uem.br; albraccini@uol.com.br ${ }^{3}$ Engenheiro Agrônomo, Mestre - Cooperativa Central de Pesquisa Agrícola/COODETEC - Br 467, Km 98 - Cx. P. 301 - 85818-660 - Cascavel, PR rrbarreto@hotmail.com 
Procurando simular condições de deficiência hídrica durante a fase de germinação das sementes, trabalhos têm sido conduzidos preferencialmente em condições de laboratório, nos quais as bases fisiológicas podem ser avaliadas satisfatoriamente como pré-requisito para condições de campo (TONIN et al., 2000). No entanto, não existem relatos na literatura nacional da avaliação da qualidade fisiológica de sementes de milho-pipoca, de diferentes genealogias, sob condição de estresse hídrico induzido. Essas informações podem ser úteis para aumentar a eficiência dos programas de melhoramento de milhopipoca no País, pois foram extraídas linhagens das principais cultivares semeadas no território brasileiro.

Diversas metodologias têm sido recomendadas para se identificar cultivares mais adaptadas às condições de estresse causadas pela baixa disponibilidade de água no solo (CAMPOS \& ASSUNÇÃO, 1990; HADAS, 1976). O polietileno glicol 6000 (PEG 6000) é um dos agentes osmóticos indicados para esse fim, por simular satisfatoriamente baixos potenciais de água, sem ser absorvido pelas sementes (MARTINELLI-SEMENE et al., 2000; VILLELA et al., 1991).

Objetivou-se, neste trabalho, avaliar a qualidade fisiológica de sementes de híbridos simples de milhopipoca, sob condição de estresse hídrico induzida por polietileno glicol.

\section{MATERIAL E MÉTODOS}

A avaliação da qualidade fisiológica das sementes de milho-pipoca foi conduzida no Laboratório de
Tecnologia de Sementes do Núcleo de Pesquisas Aplicadas à Agricultura, sendo que a multiplicação das sementes foi realizada na Fazenda Experimental de Iguatemi, ambos pertencentes à Universidade Estadual de Maringá (UEM). As sementes utilizadas neste trabalho foram obtidas a partir do Programa de Melhoramento Genético da UEM. Foram utilizadas sementes de catorze híbridos simples denominados de: A, B, C, D, E, F, G, H, I, J, K, L, M e N (Tabela 1). As linhagens S5 foram obtidas a partir das principais cultivares disponíveis aos melhoristas de milhopipoca do Brasil.

Para a obtenção do estresse hídrico, foi utilizada solução de polietileno glicol (PEG 6000). O nível de potencial osmótico utilizado foi de $-0,3 \mathrm{MPa}$, equivalendo à concentração de 148,92 g de $\mathrm{PEG} / \mathrm{L} \mathrm{H}_{2} \mathrm{O}$ desmineralizada. O nível 0,0 de potencial osmótico refere-se ao controle, com a quantidade de água equivalente a 2,5 vezes a massa do substrato seco. Para o cálculo da quantidade de PEG 6000 foi utilizada a equação proposta por Michel \& Kaufmann (1973), ou seja: $\Psi$ os $=\left(1,18 \times 10^{-2}\right) \mathrm{C}-\left(1,18 \times 10^{-4}\right) \mathrm{C}^{2}$ $+\left(2,67 \times 10^{-4}\right) \mathrm{CT}+\left(8,39 \times 10^{-7}\right) \mathrm{C}^{2} \mathrm{~T}$; em que: $\Psi$ os = potencial osmótico (bar); $\mathrm{C}=$ concentração do agente osmótico ( $\mathrm{g}$ de PEG 6000/L H2O); T = temperatura (oC).

A avaliação da qualidade das sementes foi realizada pelo teste de germinação, de comprimento da parte aérea e da raiz primária das plântulas e de biomassa seca das plântulas.

$\mathrm{O}$ teste de germinação consistiu de oito subamostras de 50 sementes, colocadas para germinar entre folhas de papel-toalha, umedecidas com as soluções, na

Tabela 1 - Origem das linhagens que foram cruzadas para obter os híbridos simples.

\begin{tabular}{cc}
\hline Híbridos Simples & \multicolumn{1}{c}{ Origem das linhagens } \\
\hline A & Linhagem extraída da cultivar Viçosa x Linhagem \\
B & extraída da cultivar Beija-Flor (UFV) \\
C & CMS 42 x UNB-2 \\
D & RS-20 x UEM-J1 \\
E & IAC 112 x BRS Angela \\
F & Zaeli x Catedral \\
G & Zélia x IAC 112 \\
H & SC 002 (UEM) x BRS Angela \\
I & BRS Angela x UNB-2 \\
J & CMS-43 x SC002 \\
K & Guarani x IAC 112 \\
L & Zélia x BRS Angela \\
M & IAC 112 x Viçosa \\
N & RS-20 x Zaeli \\
& UNB-2 x CM2-43 \\
\hline
\end{tabular}


quantidade de 2,5 vezes o peso do substrato, sendo confeccionados rolos, os quais foram levados para germinador à temperatura de $25 \pm 20 \mathrm{C}$. As avaliações foram realizadas aos quatro (primeira contagem) e sete dias (contagem final), de acordo com Brasil (1992). As plântulas normais foram ainda classificadas, para avaliação do vigor, em plântulas normais fortes e fracas, conforme metodologia proposta por Nakagawa (1999).

Para a avaliação do comprimento da raiz primária e da parte aérea das plântulas, foram utilizadas dez repetições de 20 sementes, colocadas para germinar nas mesmas condições do teste anterior por sete dias. As sementes foram distribuídas, no sentido longitudinal das folhas. Em seguida, os substratos em forma de rolos, foram colocados em sacos plásticos de coloração preta, com a finalidade de manter constante a umidade no seu interior e eliminar o efeito da luminosidade. As medições do comprimento das plântulas foram realizadas apenas nas plântulas normais (KRZYZANOWSKI et al., 1991).

A determinação da biomassa seca das plântulas foi realizada em conjunto com o comprimento das plântulas. Os eixos embrionários das plântulas provenientes de cada repetição foram colocados em sacos de papel e levados para secar em estufa com circulação forçada de ar, regulada à temperatura de $80 \pm 20 \mathrm{C}$, durante 24 horas. Após esse período, as amostras foram pesadas em balança com precisão de 0,01 grama, conforme metodologia proposta por Krzyzanowski et al. (1991). Os resultados foram expressos em g/plântula.

A partir dos dados obtidos também foi calculada a porcentagem de redução para todos os testes, quando o potencial osmótico foi diminuído para -0,3 MPa, utilizandose a fórmula: \% de redução $=x(-0,3 \mathrm{MPa}) .100 / \mathrm{x}($ controle $)-$ 100, em que: $x=$ porcentagem de redução para os testes de germinação, primeira contagem, comprimento da parte aérea, comprimento da raiz primária e biomassa seca.

O delineamento experimental utilizado foi inteiramente casualizado, com tratamentos no esquema fatorial. Os dados foram submetidos à análise de variância e na presença de interações significativas realizaram-se os desdobramentos. Para a comparação entre as médias foram utilizados os testes F e Scott-Knott, a 5\% de probabilidade.

\section{RESULTADOS E DISCUSSÃO}

Para os dados de germinação (Tabela 2) o nível de potencial osmótico de -0,3MPa foi eficiente em diferenciar os híbridos de milho-pipoca quanto à tolerância ao estresse. Provocou-se, assim, redução significativa na porcentagem de germinação com o decréscimo do potencial osmótico da solução, com exceção dos híbridos $\mathrm{G}$ e K, os quais mantiveram sua geminação praticamente constante mesmo sob estresse, apresentando-se tolerantes ao déficit hídrico. Esses híbridos simples apresentam, em sua constituição genotípica, linhagem genitora obtida da população BRSAngela. Moterle et al. (2006) indicaram a cultivar BRSAngela como tolerante ao déficit hídrico quando comparada com os híbridos de linhagens Zélia e IAC 112. Isso pode ser explicado em razão da constituição genética da cultivar BRS-Angela que possui maior número de genótipos; assim, apresenta base genética mais ampla e, portanto, maior plasticidade genética frente às variações ambientais e, provavelmente, isso deve se refletir em determinadas linhagens extraídas dessa população.

Em termos gerais, verificou-se que o potencial osmótico de -0,3MPa provocou redução em torno de 20 a $87 \%$ na porcentagem de germinação em alguns híbridos, quando comparado com os valores médios obtidos para o controle (0,0MPa). Tonin et al. (2000), também trabalhando com potencial de $-03, \mathrm{MPa}$, constararam diminuição de $45 \%$ na germinação das sementes de milho de baixo vigor.

Observa-se, por meio da Tabela 2, que, no potencial osmótico zero, os híbridos $\mathrm{E}$ e $\mathrm{N}$ apresentaram maior porcentagem de germinação sem diferirem significativamente entre si, enquanto que os híbridos B e K apresentaram as menores porcentagens de germinação. Verifica-se, ainda, que, no potencial osmótico -0,3MPa, apenas o híbrido $\mathrm{G}$ manteve germinação considerada adequada, em média de $84,2 \%$, enquanto que o híbrido $M$ apresentou a germinação mais baixa, ou seja, 24\%, com redução de 72,59\% em relação aos resultados no potencial zero $(0,0 \mathrm{MPa})$.

Nos resultados da primeira contagem da germinação (Tabela 2), verifica-se que o estresse hídrico proporcionado pelo potencial osmótico de - $-0,3 \mathrm{MPa}$ não afetou o vigor dos híbridos B, G e K na referida característica; no entanto, provocou redução significativa no vigor nos demais híbridos, quando comparados ao controle.

A redução tanto na germinação como no vigor das sementes quando o potencial osmótico foi diminuído para $-0,3 \mathrm{MPa}$, provavelmente, se deve à menor absorção de água pelas sementes, pois o aumento da concentração osmótica provoca diminuição do gradiente hídrico no sistema solo-semente (TORRES et al., 1999). Efeitos adversos de concentrações crescentes de polietileno glicol na germinação também foram encontrados por Braccini et al. (1998) e Tonin et al. (2000). Segundo Sharma (1973, 1976), citado por Torres et al. (1999), o aumento na concentração osmótica do substrato induzido pela adição do PEG 6000, provoca bloqueio no movimento de água pela diminuição do potencial hídrico reduzindo, conseqüentemente, a velocidade de germinação e do crescimento das raízes. 


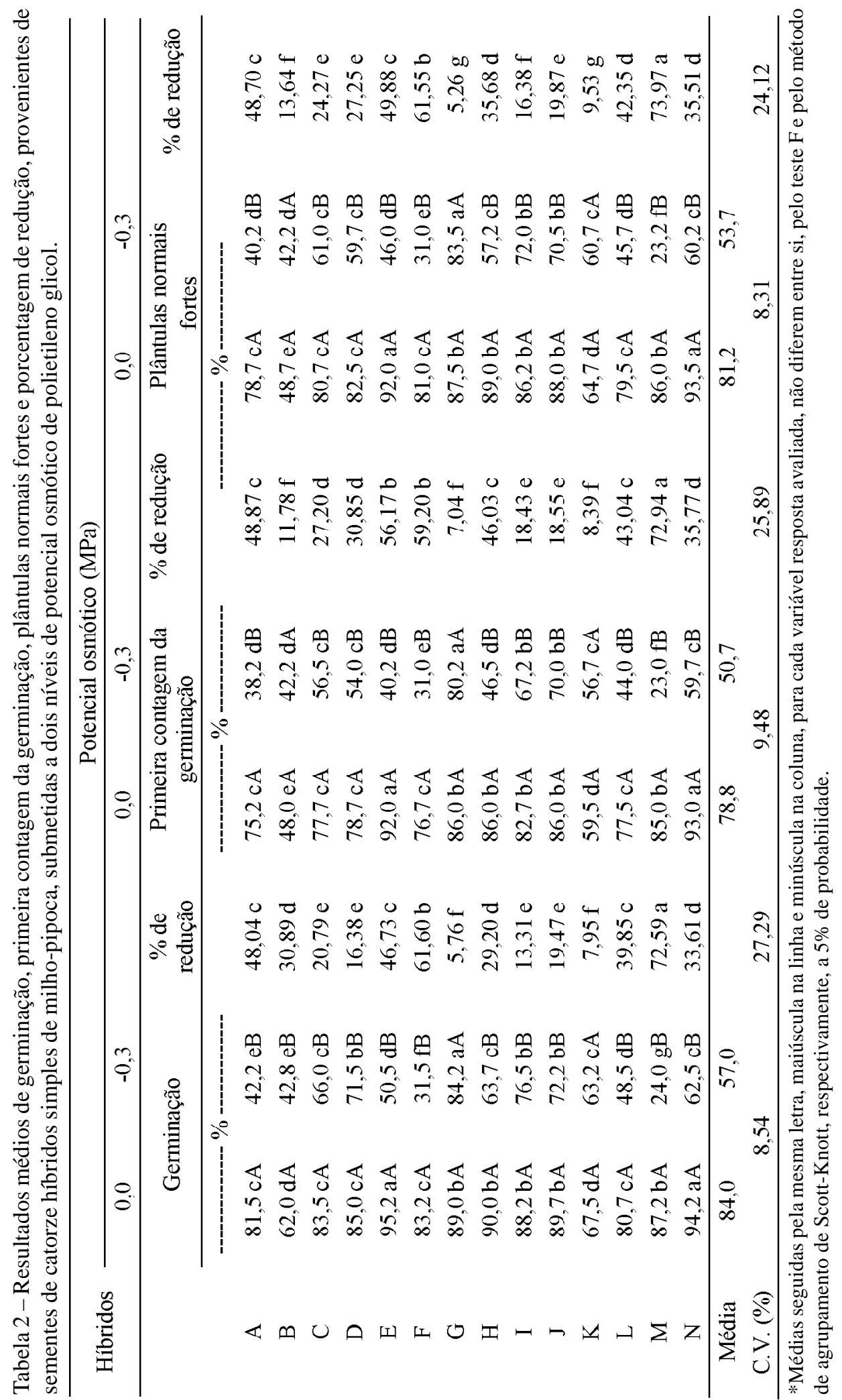


Ao comparar-se os híbridos quanto ao vigor na primeira contagem da germinação (Tabela 2), observa-se que, no potencial osmótico zero, os que apresentaram maior porcentagem de plântulas normais foram os híbridos $\mathrm{E}$ e $\mathrm{N}$, e o híbrido B foi o que apresentou a menor porcentagem. Enquanto que, para o potencial osmótico de $-0,3 \mathrm{MPa}$, o híbrido $\mathrm{G}$ apresentou maior vigor e o híbrido $\mathrm{M}$ o menor vigor na primeira contagem.

Nota-se que os híbridos $\mathrm{G}$ e $\mathrm{K}$ foram os que apresentaram a menor redução na germinação (5,76 e 7,95\%) e os híbridos B, G e K (11,78; 7,04 e 8,39\%), no vigor das sementes quando submetidos à condição de estresse. Por outro lado, o híbrido $\mathrm{M}$ foi o que apresentou a maior redução na germinação e no vigor das sementes na condição de estresse hídrico, 72, 59 e 72,94\%, respectivamente, apresentando-se como o mais susceptível à seca.

Observa-se que, nem sempre, os híbridos que apresentaram melhor qualidade inicial das sementes apresentaram maior tolerância à condição de estresse hídrico, visto que o híbrido $\mathrm{E}$ foi um dos que apresentou melhor qualidade inicial das sementes (Tabela 2), porém apresentou redução de $46,73 \%$ na germinação e de $56,17 \%$ no vigor das sementes, contrariando os resultados obtidos por Tonin et al. (2000), em que sementes de milho de alto vigor apresentaram menor queda porcentual na germinação quando submetidas ao nível de potencial osmótico $0,3 \mathrm{MPa}$. Contudo, os resultados obtidos nesse trabalho estão de acordo com aqueles relatados por Texeira (2005), porém trabalhando com sementes de soja.

Verifica-se, na Tabela 2 que, sob o potencial osmótico zero, os maiores porcentuais de plântulas normais fortes foram observados nos híbridos $\mathrm{E}$ e $\mathrm{N}$ sem diferirem significativamente entre si, enquanto que o híbrido $\mathrm{B}$ apresentou o menor porcentual $(48,7 \%)$. Sob o potencial osmótico de -0,3MPa o menor porcentual de plântulas normais fortes foi observado no híbrido $\mathrm{M}$, enquanto que apenas o híbrido $\mathrm{G}$ se sobressaiu, apresentando o maior porcentual (83,5\%). Segundo Perez (1988), as espécies comportam-se de maneira diferenciada de acordo com a condição de estresse induzido pela redução no potencial osmótico da solução. A resposta a essa condição de estresse depende não só da constituição genética, mas, também, da condição fisiológica da semente (TORRES et al., 1999).

Por meio da Tabela 2, também pode-se notar que a redução do potencial osmótico para $-0,3 \mathrm{MPa}$ provocou significativo decréscimo na porcentagem de plântulas normais fortes em praticamente todos os híbridos avaliados, com exceção dos híbridos B, G e K que mantiveram-se mais tolerantes ao estresse, sendo que os híbridos $\mathrm{G}$ e $\mathrm{K}$ foram os que apresentaram a menor porcentagem de redução, 5,26 e 9,53\%, respectivamente, na referida característica. Em contrapartida, o híbrido $\mathrm{M}$ foi o que apresentou a maior diminuição na porcentagem de plântulas normais fortes, ou seja, 73,97\%.

Para os resultados do comprimento da raiz primária e da parte aérea das plântulas (Tabela 3), observa-se semelhança com o que ocorreu para os valores de germinação e primeira contagem (Tabela 2). As diferenças foram significativas no comprimento da raiz primária e da parte aérea das plântulas em todos os híbridos, quando o potencial osmótico foi diminuído para -0,3MPa. Contudo, a redução nos valores de comprimento da parte aérea da plântula foi mais acentuada do que o efeito sobre a germinação das sementes. Tais eventos podem ser explicados pela diminuição no metabolismo das sementes, em função da menor disponibilidade de água para digestão das reservas e translocação dos produtos metabolizados, que se caracterizam por um padrão trifásico da germinação (BEWLEY \& BLACK, 1994).

Para os dados de comprimento da raiz primária das plântulas, no potencial $-3 \mathrm{MPa}$, os híbridos $\mathrm{B}, \mathrm{F}, \mathrm{G}$ e N apresentaram maior comprimento da raiz primária das plântulas, diferindo significativamente dos demais (Tabela 3). Os híbridos A, B, F, G, K e N foram os que apresentaram menor redução no comprimento da raiz primária das plântulas, enquanto que os híbridos D, I, L, e M apresentaram a maior queda porcentual no comprimento da raiz primária das plântulas.

Nota-se, também, por meio da Tabela 3 que os híbridos A, E e L apresentaram maior comprimento da parte aérea de plântulas, quando submetidos ao potencial zero, sem apresentar diferenças significativas entre si. Sob o potencial osmótico de $-0,3 \mathrm{MPa}$ o híbrido $\mathrm{D}$, seguido pelo $\mathrm{E}$, apresentaram os melhores resultados, enquanto que os híbridos F, L e M foram os mais afetados pelo estresse. Observa-se também que, ao se diminuir o potencial osmótico para $-0,3 \mathrm{MPa}$, a menor redução ocorreu nos híbridos D (39,15\%) e N (43,93\%), enquanto que os híbridos F, L e M apresentaram maior redução na parte aérea.

Além do estresse hídrico afetar a embebição, a velocidade e a porcentagem de germinação, Kramer (1974), citado por Braccini et al. (1996), relatou que o primeiro efeito mensurável da baixa disponibilidade de água é uma redução no crescimento, ocasionada pela diminuição da expansão celular. O processo de alongamento celular e a síntese de parede são muito sensíveis ao estresse hídrico e, de acordo com Yasseen \& Alomary (1994), a redução do crescimento seria causada por decréscimo da turgescência dessas células, exercendo efeito negativo principalmente na fase inicial da expansão celular. 


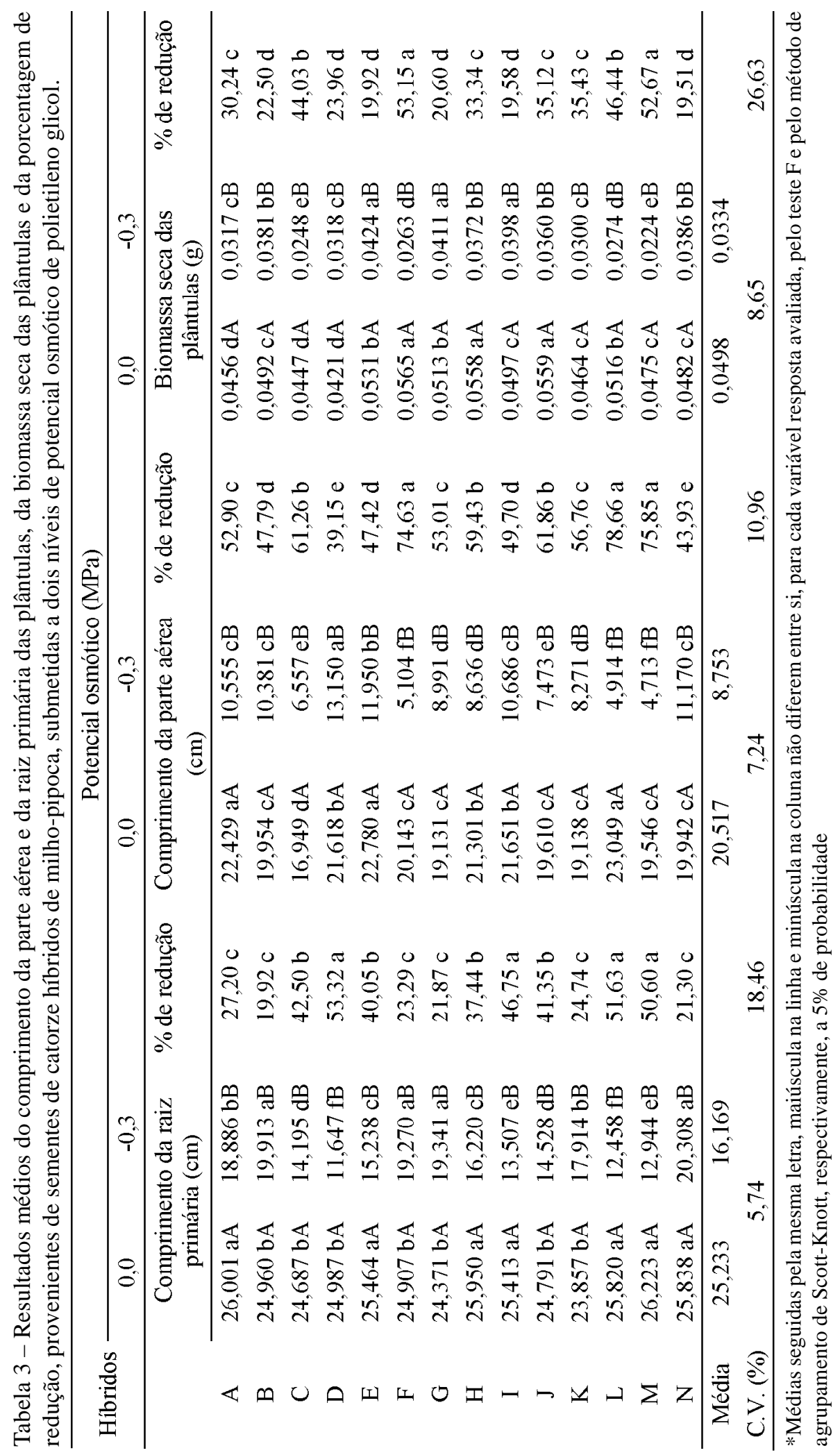


No que se refere à biomassa seca da plântula (Tabela 3), observou-se que, sob o potencial de -0,3MPa, houve maior decréscimo na absorção de água pelas sementes, acarretando uma redução significativa na biomassa seca das plântulas, quando comparadas ao nível zero. Segundo Sá (1987), a menor absorção de água pelas sementes reduz a velocidade dos processos fisiológicos e bioquímicos. Com isso, as plântulas resultantes desse meio, com menor grau de umidade, apresentam menor crescimento, caracterizado por menores comprimentos da plântula e menor acúmulo de biomassa seca.

Ao compararem-se os híbridos, nota-se que os híbridos F, H e J apresentaram maior acúmulo de biomassa seca das plântulas no potencial osmótico zero, ao passo que, no potencial de $-0,3 \mathrm{MPa}$, os híbridos que mais se destacaram foram o $\mathrm{E}, \mathrm{G}$ e I, sendo que os híbridos $\mathrm{C}$ e $\mathrm{M}$ apresentaram o menor acúmulo de biomassa seca. $\mathrm{O}$ menor porcentual de redução no acúmulo de biomassa seca com a diminuição do potencial para $-0,3 \mathrm{MPa}(22,50 ; 23,96 ; 19,92$; 20,60; 19,58 e 19,51\%) foi observado nos híbridos B, D, E, $\mathrm{G}$, I e N, respectivamente, e a maior redução ocorreu nos híbridos F e M (redução de 53,15 e 52,67\%).

Conforme foi observado neste estudo, o potencial osmótico - $0,3 \mathrm{MPa}$ de polietileno glicol provoca a redução no desempenho das sementes. Dessa maneira, sugere-se acrescentar a essa pesquisa informações acerca do estabelecimento das plântulas de milho-pipoca em áreas propensas a estiagem, correlacionando plântulas e germinação de sementes quanto ao aspecto tolerância ao déficit hídrico, para que se possa permitir seleção criteriosa de híbridos tolerantes à seca. Além disso, o uso de soluções de polietileno glicol em análises de rotina de germinação poderia ser alternativa para se estimar o vigor das sementes sob estresse hídrico.

\section{CONCLUSÕES}

A diminuição do potencial hídrico do substrato é prejudicial à germinação das sementes e ao crescimento das plântulas de milho-pipoca.

Os híbridos G e K são os mais tolerantes ao estresse hídrico. $\mathrm{O}$ híbrido $\mathrm{M}$ se mostrou mais susceptível à seca.

A tolerância ao estresse hídrico independe da qualidade inicial das sementes de milho-pipoca.

\section{REFERÊNCIAS BIBLIOGRÁFICAS}

BANSAL, R. P.; BHATI, P. R.; SEN, D. N. Differential specificity in water inhibition of Indian arid zone. Biologia Plantarum, Copenhague, v. 22, n. 5, p. 327-331, 1980.
BEWLEY, J.; BLACK, M. Seeds: physiology of development and germination. 3. ed. New York: Plenum, 1994. $445 \mathrm{p}$.

BRACCINI, A. L.; REIS, M. S.; SEDIYAMA, C. S.; SEDIYAMA, T.; ROCHA, V. S. Influência do potencial hídrico induzido por polietilenoglicol na qualidade fisiológica de sementes de soja. Pesquisa Agropecuária Brasileira, Brasília, v. 33, n. 9, 1998.

BRACCINI, A. L.; RUIZ, H. A.; BRACCINI, M. C. L.; REIS, M. S. Germinação e vigor de sementes de soja sob estresse hídrico induzido por soluções de cloreto de sódio, manitol e polietileno glicol. Revista Brasileira de Sementes, Pelotas, v. 18, n. 1, p. 10-16, 1996.

BRASIL. Ministério da Agricultura e Reforma Agrária. Regras para análise de sementes. Brasília, DF: SNAD/ DNDV/CLAV, 1992. 365 p.

CAMPOS, I. S.; ASSUNÇÃO, M. V. Efeitos do cloreto de sódio na germinação e vigor de plântulas de arroz. Pesquisa Agropecuária Brasileira, Brasília, v. 25, n. 6, p. 837-843, 1990.

DURÃES, F. M.; CHAMMA, H. M. C. P.; COSTA, J. D.; MAGALHÃES, D. C.; BORBA, C. S. Índices de vigor de sementes de milho (Zea mays L.) associados com emergência no campo e rendimento de grãos. In: CONGRESSO BRASILEIRO DE FISIOLOGIA VEGETAL, 4., 1993, Fortaleza, CE. Revista Brasileira de Fisiologia Vegetal, v. 5, n. 1, p. 90, 1993.

HADAS, A. Water uptake and germination of leguminous seeds under changing external water potencial in osmotic solution. Journal of Experimental Botany, Oxford, v. 27, n. 98, p. 480-489, 1976.

KRZYZANOWSKI, F. C.; FRANÇA NETO, J. B.; HENNING, A. A. Relato dos testes de vigor disponíveis para as grandes culturas. Informativo Abrates, Londrina, v. 1, n. 2, p. 15-50, 1991.

MARTINELLI-SENEME, A.; MARTINS, C. C.; NAKAGAWA, J. Germinação de milho cv. AL-34 em função do tamanho da semente e do potencial hídrico do substrato. Revista Brasileira de Sementes, Pelotas, v. 22, n. 2, p. 126130, 2000. 
MICHEL, B. E.; KAUFMANN, M. R. The osmotic potential of polyethylene glycol 6000. Plant Physiology, Lancaster, v. 51, n. 6, p. 914-916, 1973.

MOTERLE, L. M.; LOPES, P. C.; BRACCINI, A. L.; SCAPIM, C. A. Germinação de sementes e crescimento de plântulas de cultivares de milho-pipoca submetidas ao estresse hídrico e salino. Revista Brasileira de Sementes, Pelotas, v. 28, n. 3, p. 169-176, 2006.

NAKAGAWA, J. Testes de vigor baseados no desempenho das plântulas. In: KRZYZANOWSKI, F. C.; VIEIRA, R. D.; FRANÇA NETO, J. B. Vigor de sementes: conceitos e testes. Londrina: Abrates, 1999. p. 2.1-2.21.

PEREZ, S. C. J. G. A. Aspectos ecofisiológicos da germinação de sementes de algarobeira. 1988. $214 \mathrm{f}$. Tese (Doutorado) - Universidade Federal de São Carlos, São Carlos, 1988.

POPINIGIS, F. Fisiologia da semente. Brasília, DF: Agiplan, 1985. 289 p.

SÁ, M. E. Relações entre qualidade fisiológica, disponibilidade hídrica e desempenho de sementes de soja (Glycine max (L.) Merrill). 1987. 147 f. Tese (Doutorado) - Escola Superior de Agricultura de Luiz de Queiroz, Piracicaba, 1987.
TAIZ, E.; ZEIGER, L. Fisiologia vegetal. 3. ed. Porto Alegre: Artmed, 2004. 719 p.

TEXEIRA, L. R. Avaliação de cultivares de soja quanto à tolerância ao estresse hídrico pelo método do papel-solução contendo polietileno glicol. 2005. 67 p. Dissertação (Mestrado) - Universidade Federal do Paraná, Maringá, 2005.

TONIN, G. A.; CARVALHO, N. M.; KRONKA, S. N.; FERRAUDO, A. S. Influência do cultivar e do vigor no desempenho germinativo de sementes de milho em condições de estresse hídrico. Revista Brasileira de Sementes, Pelotas, v. 22, n. 1, p. 276-279, 2000.

TORRES, S. B.; VIEIRA, E. L.; MARCOS-FILHO, J. Efeitos do estresse hídrico na germinação e no desenvolvimento de plântulas de pepino. Revista Brasileira de Sementes, Pelotas, v. 21, n. 2, p. 59-63, 1999.

VILLELA, F. A.; DONI-FILHO, L.; SEQUEIRA, E. L. Quadro de potencial osmótico em função da concentração de polietileno glicol 6000 e da temperatura. Pesquisa Agropecuária Brasileira, Brasília, v. 26, n. 11/12, p. 19571968, 1991.

YASSEEN, B. T.; ALOMARY, S. S. An analysis of the effects of water-stress on leaf growth and yield of 3 barley cultivars. Irrigation Science, New York, v. 14, n. 3, p. 157162, 1994. 